\title{
The headache of
}

Biotechnology companies face an elusive threat—how to handle what they know, says John Hodgson

inding a profitable niche for biotechnology within health care and agriculture is tricky enough if you are the CEO of a large, wellestablished, and well-funded company, but spare a thought for the beleaguered CEO of a younger business. $\mathrm{His} /$ her job is mademuch harder by investors' demands for multi-fold returns on investments, the inability to offer the salaries needed to attract the best employees, and the management of a commodity that is intangible, volatile,

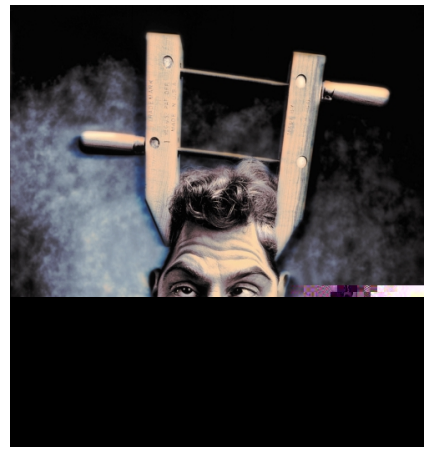
and difficult-to-handleknowledge.

Biotechnology is undeniably part of the knowledge economy. Young companies, in particular, may have few tangible assets other than their specific and detailed knowledge of a given area of technology. Yet despiteits fundamental importance, knowledge often appears to be a highly undervalued asset for many biotechnology companies.

A recent survey of UK life science companies indicated that although many recognized theimportance of effectiveknowledge management, few considered that a deficiency in knowledge management would pose a business risk (seeH enderson p. BE20). Ironically, younger companies were proneto holding this attitude, perhaps because at this stage of their development other matters (e.g., financing and staffing) seem more pressing. However, even when managers did recognize the risk, they invested very little time in knowledge management ${ }^{1}$.

\section{The tip of the iceberg}

Knowledge clearly creates corporate

John H odgson is Editor-at-Large at Nature Biotecnhology. converts intellectual activity into a clearly defined commercial opportunity and thus tradable value.

Furthermore, patents are one of the few things that can't walk out of the door! The biotechnology sector is in constant flux, and personnel and management migrate from company to company. Companies recognize that a free flow of information from the company can undermine its technical or commercial position, and they apply sensible restrictions to the efflux of knowledge. Contractual restrictions, such as the inclusion of non-compete or confidentiality clauses in employment agreements, may prevent competitors learning too much about a company's vital information, but they cannot prevent the information lost with departing staff.

Companies can enforce policies limiting commenting to the media, and may permit only designated (senior) staff to talk in detail with potential collaborators on research programs and commercial activities.

However, knowledge management in a biotechnology company must encompass more than patent filings and staff "gagging". A company's information and knowledge assets arise from many quarters- both internally and externally. For example, an increasing reliance on outsourcing and data sharing ( particularly in genomics) means that much of the potential knowledge resources are generated outside a company. H owever, whether from internal or externally generated data, knowledge and information is held initially by individuals and not the body corporate.

\section{Knowledge harnessed}

The end product of good knowledge management procedures is "harnessed" knowledge- knowledge that can be readily put to use on behalf of all relevant members 
the company should operate in much the same way.

Just as a company would draw up a budget by discussing the financial needs of its various function, so it should establish information and knowledge needs through a formal process that involves departmental and group heads as well as the senior management. That process defines not only what knowledge is needed and who should endeavor to garner it, but also who needs to be informed subsequently. That definition will lead to a description of a knowledge management system, almost certainly intranet-based, that both helps fulfill individual information needs and in effect monitors the company's collective knowledge store.

That process of defining the information needs will help employees understand better their role in the knowledge machine that is the company they work for. For instance, researchers understand that the results of their experiments are important to the company. However, if they have come from academic backgrounds, they may be less clear on what they can say about their own work at scientific meetings or what might be of interest in other people's presentations. A company's management can clarify these definitions, and provide, through the knowledge management system, a reporting outlet that will channel information around the organization.

Clearly, much of the information generated in a company is not needed by all employees. Information flows need to be filtered so that raw data from every microtiter plate well or the notes from the day's sales calls do not obscure more important messages.

A knowledge management system does not have be burdensome: indeed, if it is, it will not be used. The system will also encompass natural hierarchical information flows. Research staff will naturally inform their group leaders of progress and significant devel opments; sales and marketing staff speak with their supervisors about new leads. But a knowledge management system will help ensure that that occurs consistently. It will al so contain triggers and alerting mechanisms that draw out information that might not otherwise be forthcoming.

Equally importantly, a knowledge management system needs to have an element of self-sustainability. M anagement can urge or incentivize employees to use the knowledge management apparatus, but the greatest encouragement will arise when an employee finds something in it that is useful or vital to him or her.

Knowledge management may not be at the top of most companies' lists of business risks, but deficiencies in knowledge management erode the performance of biotechnology companies' distinguishing assetstheir intellectual engines. In essence, then, the ideal knowledge management system for a biotechnology company needs to combine the properties of a black hole with those of a small sun: it draws information and knowledge toward it but then re-emits it in appropriate beneficent doses in a variety of directions.

1. Arthur Andersen. Managing risk, building value: risk management in the UK life sciences. (Arthur Andersen, London, UK, 2001). 
the company should operate in much the same way.

Just as a company would draw up a budget by discussing the financial needs of its various function, so it should establish information and knowledge needs through a formal process that involves departmental and group heads as well as the senior management. That process defines not only what knowledge is needed and who should endeavor to garner it, but also who needs to be informed subsequently. That definition will lead to a description of a knowledge management system, almost certainly intranet-based, that both helps fulfill individual information needs and in effect monitors the company's collective knowledge store.

That process of defining the information needs will help employees understand better their role in the knowledge machine that is the company they work for. For instance, researchers understand that the results of their experiments are important to the company. However, if they have come from academic backgrounds, they may be less clear on what they can say about their own work at scientific meetings or what might be of interest in other people's presentations. A company's management can clarify these definitions, and provide, through the knowledge management system, a reporting outlet that will channel information around the organization.

Clearly, much of the information generated in a company is not needed by all employees. Information flows need to be filtered so that raw data from every microtiter plate well or the notes from the day's sales calls do not obscure more important messages.

A knowledge management system does not have be burdensome: indeed, if it is, it will not be used. The system will also encompass natural hierarchical information flows. Research staff will naturally inform their group leaders of progress and significant devel opments; sales and marketing staff speak with their supervisors about new leads. But a knowledge management system will help ensure that that occurs consistently. It will al so contain triggers and alerting mechanisms that draw out information that might not otherwise be forthcoming.

Equally importantly, a knowledge management system needs to have an element of self-sustainability. M anagement can urge or incentivize employees to use the knowledge management apparatus, but the greatest encouragement will arise when an employee finds something in it that is useful or vital to him or her.

Knowledge management may not be at the top of most companies' lists of business risks, but deficiencies in knowledge management erode the performance of biotechnology companies' distinguishing assetstheir intellectual engines. In essence, then, the ideal knowledge management system for a biotechnology company needs to combine the properties of a black hole with those of a small sun: it draws information and knowledge toward it but then re-emits it in appropriate beneficent doses in a variety of directions.

1. Arthur Andersen. Managing risk, building value: risk management in the UK life sciences. (Arthur Andersen, London, UK, 2001). 